\title{
Estimation and Calibration of Thermal Neutron Flux for Neutron Activation Analysis
}

\author{
Sang-Tae Park and Nak Han Jang \\ Institute of Science Education, Kongju National University. Kongiu. Chungnam 314-701, Korea \\ ${ }^{\dagger}$ Department of Science Education, Kongju National Lniversin of Education, Kongulu. Chumgnam 314-711, Korea \\ ${ }^{*} E$-mail: nhjangiăgiue ac.kr \\ Received Mav 18, 2006
}

Key Words : Element analysis, Capture cross section. Neutron activation method. Neutron flux

\begin{abstract}
Neutron activation analy'sis (NAA) is a very sensitive. powerful teclunique for identifying characteristics of many elements through performing both qualitative and quantitative analysis of major. minor. and trace elements in samples from almost every conceivable field of scientific or teclunical interest. ${ }^{1 .}$ Basically this technique is quite simple. A sample is irradiated by thermal neutrons and becomes radioactive. By measuring the $\beta^{-} \mathrm{s}, \gamma_{\mathrm{s}}, \beta^{-} \mathrm{s}$. and half-life of the activated sample. the elemental constituents of the sample and their relative concentrations can be identified.

Industrial activation analysis is usually done with thermal neutrons from a reactor. where the neutron flux can be as high as $\sim 10^{13}$ neutrons $/ \mathrm{cm}^{2} / \mathrm{s}$. or with an accelerator with fast neutron fluxes of $\sim 10^{13}$ neutrons $/ \mathrm{cm}^{2} / \mathrm{s}$. When activation analysis is compared with other instrumental analytical methods such as gravimetric calorimetric. spectrographic. or mass spectroscopy. its sensitivity is usually shown to be better over a factor of 10 than that of other methods. Activation analysis is used extensively in such fields as geolog: medicine, agriculture. electronics. metallurgy. criminology. and the petroleum industry. ${ }^{3.4}$
\end{abstract}

\section{Theoretical Background}

Assume that the sample has been activated in the accelerator. At the instant when the activation has been terminated. $(\mathrm{t}=0$ ), the activity of the sample is given by the following expression:

$$
A_{0}=\frac{\sigma m \eta \phi \alpha S}{1:}
$$

where

$A_{\text {(1) }}$ : the number of disintegrations per second of the element in the sample at $\mathrm{t}=0$ (when irradiation stops).

$\sigma$ : cross section for the reaction. $\mathrm{cm}^{2}$

$m$ : mass of the target element. $\mathrm{g}$.

$\eta$ : Avogadro's number. $6.023 \times 10^{23}$ molecules $/$ mole.

$\phi$ : neutron flux neutrons $/ \mathrm{cm}^{2} / \mathrm{sec}$.

$\alpha$ : fraction of the target isotope in the sample [e.g.. with an ordinary copper sample producing the ${ }^{63} \mathrm{Cu}(\mathrm{n} . \eta)^{64} \mathrm{Cu}$ reaction. $\alpha=0.69$ since $69 \%$ of all natural copper is $\left.{ }^{63} \mathrm{Cu}\right]$.

$S:$ saturation factor. $1-e^{-i t}$. where $\lambda=0.693 / T_{1: \text { and }} T_{1:}$ is the half-life for the reaction.
' ' : atomic weight of the element.

After irradiation the sample is transferred immediately to the high purity germanium (HPGe) detector. and a spectrum is accumulated for a time. $\left(t_{1}\right)$. long enough to get reasonable statistics under the photo peak. The time is usually at least one half-life. The true number of disintegration, $\left(N_{d}\right)$. that occurred during $t_{1}$ can be determined from the following equation. ${ }^{5}$

$$
N_{d}=\frac{\Sigma_{p}-\Sigma_{\beta}}{G \varepsilon_{p} f}
$$

where

$\Sigma_{p}$ : sum under the photo peak.

$\Sigma_{\beta}$ : background for the same counting period under the photo peak,

$G: A / 2 \pi s^{2}$. where $A=$ area of detector in $\mathrm{cm}^{2}$, and $s=$ distance from source to detector in $\mathrm{cm}$.

$\varepsilon_{p}$ : intrinsic peak efficiency for the $\gamma$ energy and detector size used.

$f$ : decay fraction of the unknown activity, which is the fraction of the total disintegrations in which the measured gamma is emitted.

From the decay equation. $N_{i j}$ can be calculated

$$
\begin{aligned}
& N_{i d}=N_{i}\left(1-e^{-i t}\right)(\mathrm{t}: \text { measurement time }) \\
& A_{i j}=\lambda N_{i j}
\end{aligned}
$$

where $t$ is the time for which the sample was counted.

Generally, radiation decay equation is following.

$$
N=N_{i} e^{-i l i t}
$$

where

$N$ : number of neutron with the absorber.

$N_{i j}$ : number of neutron without absorber.

$\mu_{\mathrm{f}}:$ linear absorption coefficient.

$t$ : thickness of absorber.

and definition of total cross section is

$$
\sigma_{T}=\frac{\mu_{t}}{n}
$$

where $n$ is the number of nuclear in absorber such as following: 


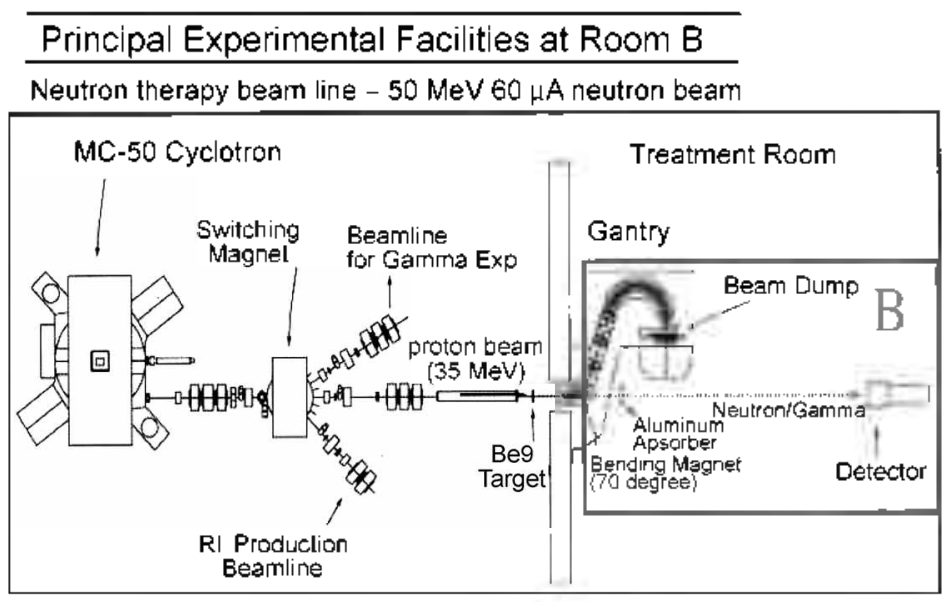

Figure 1. Dlagram of MC 50 cyclotron facility un KIRAMS.

$$
n=\frac{\rho \times N_{-t}}{A}
$$

where $\rho$ is density of absorber, $N_{A}$ Avogadro's number. and $A$ atomic weight.

If we put equation (5) in equation (4). neutron cross section is following

$$
\begin{aligned}
N & =N_{\mathrm{i}} e^{-\sigma_{T^{3 j t}}} \\
T & =e^{-\sigma_{T^{n}} t t} \\
\sigma_{T} & =\frac{\ln T}{n t}
\end{aligned}
$$

\section{Experiments}

In this study $50 \mathrm{MeV}$ cyclotron (MC50) in Korea Institute of Radiological \& Medical Science (KIRAMS) was used for neutron source by Be(p. n) reaction (Figure 1). And thermal neutron flux was generated using $10 \mathrm{~cm} \phi \times 5 \mathrm{~cm}$ cy lindrical polyethylene. We used gold thin film to estimate the flux of thermal neutron by cylindrical polyethylene and measured the spectrum of the activated gold thin film using $2 " \phi$ HPGe detector (Figure 2). From the result of this Figure 2, we can calculate the thernal neutron flux. To get the activity exactly, we must also know the efficiency of HPGe detector. In this study. ${ }^{2} \mathrm{Na}{ }^{55} \mathrm{Mn},{ }^{57} \mathrm{Co},{ }^{104} \mathrm{Cd} .{ }^{135} \mathrm{Cs}$ standard source were used for getting the efficiency and the energy calibration curve of detector (Figure 3). Because we used point source and the sample was not a same geometry, we corrected it using simulation program. To confinn the evaluated thermal neutron flux from activated gold thin film. we activated ${ }^{55} \mathrm{Mn}$ sample and got the cross section from ${ }^{55} \mathrm{Mn}(\mathrm{n}, \gamma){ }^{56 \mathrm{Mn} \text { reaction. }}$

\section{Results and Discussion}

We took the gamma-ray spectrum of the activated gold thin film using HPGe detector. and was showed in Figure 2. From the result of this Figure 2. we calculated the thermal

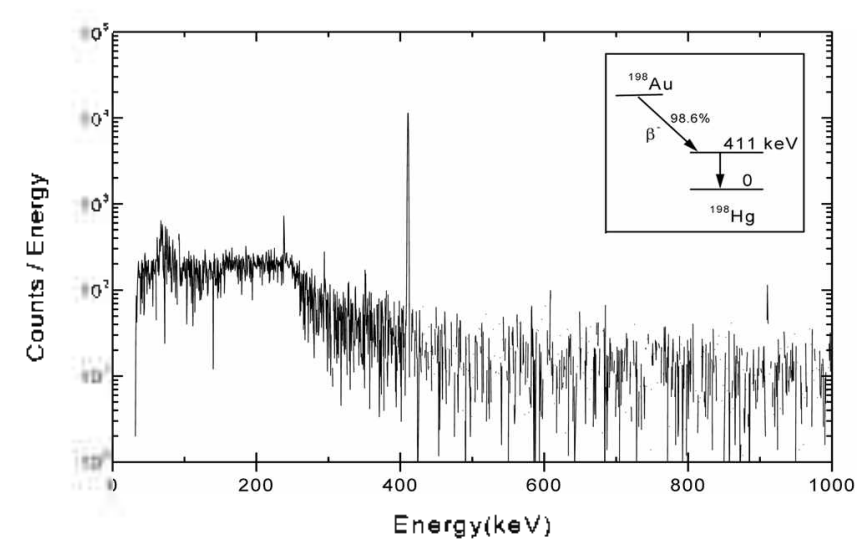

Figure 2. Gamma ray pulse height spectrum by ${ }^{19-} \mathrm{Aul}(\mathrm{n}, y)^{198} \mathrm{All}$ reaction.

neutron flux in the $411 \mathrm{keV}$ gamma ray peak area and its thermal neutron flux was 19426.68 as shown in Table 1. And also. detector efficiency of $411 \mathrm{keV}$ gamma ray energy was estimated to about $0.24 \%$. If we use the efficiency curve and the energy calibration curve of detector. we can know how

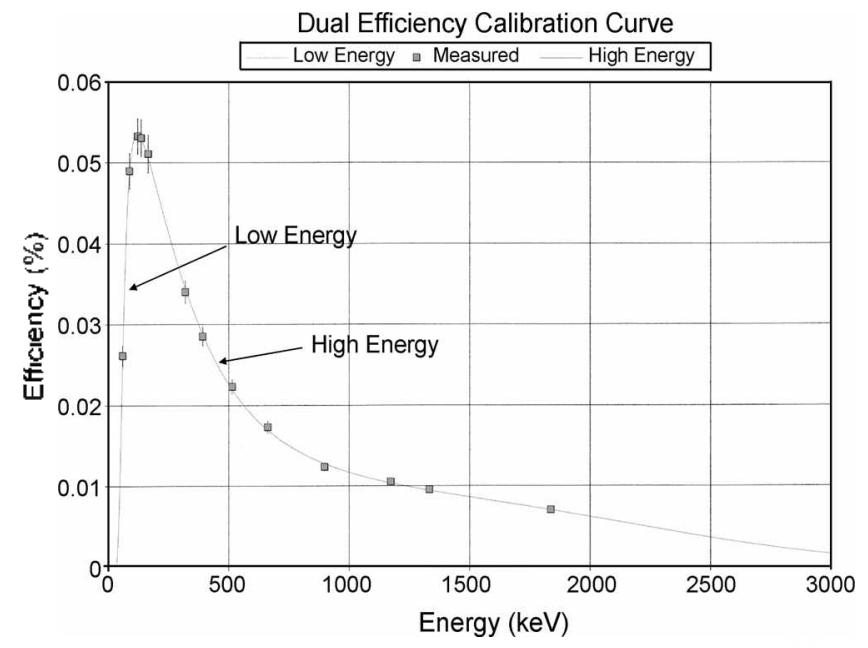

Figure 3. Absolute efficiency of HPGe detector (distance from detector to source: $10 \mathrm{~cm}$ ). 
Table 1. Evaluation of thermal neutron flux

\begin{tabular}{cccccc}
\hline $\begin{array}{c}\gamma \text { ray } \\
\text { energy }\end{array}$ & $\begin{array}{c}\text { peak } \\
\text { area }\end{array}$ & $\begin{array}{c}\text { efficiency } \\
(\%)\end{array}$ & mass $(\mathrm{g})$ & $\begin{array}{c}\text { saturation factor } \\
\left(1-e^{-\lambda_{3}}\right)\end{array}$ & $\begin{array}{c}\text { flux } \\
\left(\mathrm{N} / \mathrm{cm}^{2} \cdot \mathrm{sec}\right)\end{array}$ \\
\hline $411 \mathrm{keV}$ & 15086.15 & 0.24 & 0.072 & 0.869 & $19426.68 \pm 101.62$ \\
\hline
\end{tabular}

Table 2. I hemal neutron capture cross section of ${ }^{5} \mathrm{Mn}$

\begin{tabular}{cccccc}
\hline $\begin{array}{c}\text { ray } \\
\text { energy }\end{array}$ & $\begin{array}{c}\text { peak } \\
\text { area }\end{array}$ & $\begin{array}{c}\text { efficiency } \\
(\%)\end{array}$ & mass $(\mathrm{g})$ & $\begin{array}{c}\text { saturation factor } \\
\left(1-e^{-\lambda_{s}}\right)\end{array}$ & $\begin{array}{c}\text { cross section } \\
(\text { barn })\end{array}$ \\
\hline $847 \mathrm{keV}$ & 1004.34 & $9.53 \times 10^{-2}$ & 0.527 & 0.998 & $13.79 \pm 0.45$ \\
\hline
\end{tabular}

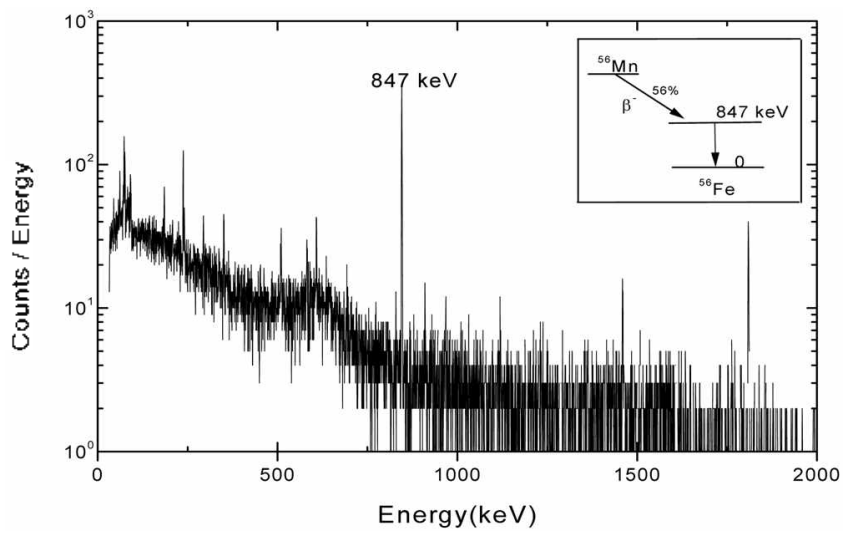

Figure 4. Gamma ray pulse height spectrum by ${ }^{\leq s} \mathrm{Mn}(\mathrm{n}, y)^{50} \mathrm{Mn}$ reaction.

many thermal neutron get into the activated sample. In the case of ${ }^{198} \mathrm{Au}$. when gold thin film was exposed to thermal neutron flux during 18 hour. saturation factor was calculated to 0.869 with 2.696 days half-life for $0.072 \mathrm{~g}$ gold thin film mass in $1 \mathrm{~cm}$ diameter. From this data. we could evaluated the thermal neutron flux of gold thin film using MC50 in $\operatorname{Be}(\mathrm{p} . \mathrm{n})$ reaction and the estimated data were listed in Table 1 .

To confirm the above result of thermal neutron flux using MC50. we took the gamma-ray spectrum and calculated themmal neutron capture cross section of $\mathrm{Mn}$. The ganumaray spectrum from ${ }^{5} \mathrm{Mn}$ produced by neutron activation of the $\mathrm{Mn}$ was shown in Figure 4 . Using the previous same method for gold thin film. we could calculated the capture cross section of ${ }^{5} \mathrm{Mn}$ from equation 1 . The result of these calculation was listed in Table 2. Themal neutron capture cross section of ${ }^{5 i} \mathrm{Mn}$ was estimated about 13.79 barn whereas the reported was about 13.41 bam. This have a good agreement with the reported in table of isotope by other method.

Our neutron activation method can be used to analyze very small amount of element in various sample. If unknown samples are exposed to thermal neutron from MC50 during selected time. we can measure the gamma ray spectrum from activated sample by (n. y) reaction and can administer quantitative analysis of the sample. This is called by Nuclear Analytical Tecliniques (NAT). This teclnique is very advanced with HPGe detector and development of personal computer. So we can identify the unknown element through quantitative analysis using neutron activation method rapidly and exactly. Further. this technique will be helpful to background monitoring of very small amount element. source receptor model and controling air pollution. ${ }^{7}$

\section{References}

1. Altassi. Z. B. Instmmental Multi-Element Chemical Analwsis: Kluwer Academic Publishers: Dordrecht. Netherland. 1998.

2. Gray, D.: McKown, D. M; Kay. M:; Eichor. M: Vogt, J. R. IEEE Trans. Nucl. Sci. 1972.19, 194.

3. Bode. P. Anal Bioanal. Chem. 2004, 379. 181

4. Chun. K. S.: Lee. C. Czae, M. Z; Lee, J. D; Chung. K. S. $J$. Korean Chem. Soc. 1993. 37, 961 .

5. Palmer. H. E. IEEE Trans Nicl Sci. 1970. 17. 138.

6. Table of Isotopes. 7th ed.: Lederer. C. M.: Shirley. V. S.. Eds.: Joln Wiley \& Sons. Inc.: New York. U. S. A.. 1978.

7. Sim. J. H.: Kim. M.: Park, S.; Bang. J. H.; Sohn, D. Bull Koream Chem. Soc. 2006, 27.251. 